\title{
Los agravios reificantes hacia los «indios» como problema ante la filosofía de la comprensión
}

\author{
Jorge Francisco AGUIRRE SALA ${ }^{i}$
}

\begin{abstract}
RESUMEN:
La Conquista y el dominio de América provocaron la «reificación», es decir, la cosificación del referente «indio». Ello plantea un reto todavía actual y también ejemplar para otras latitudes del orbe, dada la pluralidad étnica contemporánea: la superación de esta injusta reificación por medio de la comprensión más allá del mero conocimiento. Dicho en términos modernos: el reconocimiento efectuado en tres momentos: 1) concientización de la praxis agraviante hacia «los indios» en la Colonia y época post-colonial; 2) la interpretación de lo ajeno desde lo propio y su apropiación y, 3) el desenlace a la pluralidad cultural.
\end{abstract}

PALABRAS CLAVE: reificación, interpretación, asimilación, apropiación, perspectiva histórica, pluralidad.

\begin{abstract}
:
The colonization and domination of America led to «reification», that is, reifying the term «indian». This raises a current and also exemplary challenge, to other parts of the world, given the contemporary ethnic plurality: overcoming this unjust reification through understanding beyond mere knowledge. To put it in modern terms: the acknowledgement of the fusion of significant horizons, accomplished in three moments: 1) the awareness of the offensive practice towards «the Indians» in the Colonial and post-colonial era; 2) the interpretation of the foreign from the self and its appropriation; and 3) the outcome of cultural plurality.
\end{abstract}

KEYWORDS: reification, interpretation, assimilation, appropriation, historical perspective, plurality.

\section{Introducción}

La Conquista y dominio de América latina provocó una cosificación étnica que todavía hoy obliga a evaluar su problemática. Además, representa una oportunidad de aportar soluciones a otras latitudes del orbe donde la dominación de una etnia sobre otras ha cometido la misma injusticia de reificación. Por otra parte, también representa una evaluación de las pretensiones de universalidad de algunas propuestas nacidas en el eurocentrismo. Para librarse del eurocentrismo en América Latina durante décadas se debatió sobre la originalidad de lo latinoamericano; lo atestiguan las consabidas réplicas entre Salazar Bondy y Leopoldo Zea; la exposición de las temáticas indigenistas por Luis Villoro; del mestizaje por Andrés Molina Enríquez y la prospectiva utópica de José 
Vasconcelos; la discusión de la identidad continental o mexicana en ensayos ya clásicos de Octavio Paz y Samuel Ramos respectivamente. A lo anterior hay que sumar en el último lustro las aplicaciones de la Hermenéutica ante el problema de la diversidad, la diferencia y los choques entre distintas tradiciones.

Evaluar la reificación que sufrió la población autóctona latinoamericana apunta a revisar los procesos identitarios, de reconocimiento y de comprensión, por encima de la mera explicación; necesarios para evitar enfrentamientos estériles e injusticias. Es un desafío para evitar conflictos y obtener el enriquecimiento cultural. Y ese reto se aborda bajo la siguiente hipótesis: la filosofía de la comprensión aplicada al pluralismo indoamericano aporta el reconocimiento y su valoración, y no sólo su conocimiento. Además, produce el enriquecimiento de la propia percepción obteniendo una justificación de la pluralidad cultural. Para lograr dicho reconocimiento se desarrollan las secciones de los tres momentos indicados en el resumen del inicio.

\section{La praxis agraviante hacia «los indios» en la Colonia y época post-colonial}

En la época Colonial de América latina el progreso, entendido como culturización civilizatoria y evangelizadora, provocó la imposición de una cultura sobre otras bajo el pretexto de una supuesta superioridad. La pretendida superioridad de los «no indios» afectó no sólo a los indígenas, sino también a los mestizos y, paradójicamente, a los mismos «no indios».

Los «conquistadores» de América y también algunos «evangelizadores» no procuraron el reconocimiento de los autóctonos, sino que los encasillaron en sus «civilizados» y «cristianizados» parámetros. Esto se tradujo en la considerable amenaza o destrucción de las tradiciones indígenas. Transcurridas algunas generaciones y con la inevitable mezcla de etnias, inclusive el mestizo se incorporó como una figura más del «no indio» dominante. El mestizo no fue capaz de reconocer su propia raíz indígena, peor aún, «utilizó al indígena como objeto o herramienta para su propio beneficio» .

${ }^{1}$ L. VILLORO, Los grandes momentos del indigenismo en México, México, El Colegio de México, El Colegio Nacional, FCE., 1998. 
Tanto en la Colonia como en la época post-independentista los «no indios» adoptan una postura hermética e indiferente respecto a la identidad indígena desde sí misma; pues el reconocimiento o es falso o nulo. Y como Taylor ha indicado, un reconocimiento falso es peor que la falta misma del reconocimiento; porque la identidad se moldea en gran parte por el reconocimiento y el falso reconocimiento de un individuo, o bien, de un grupo, puede causar un considerable daño a manera de «una auténtica deformación» ${ }^{2}$. El falso reconocimiento es grave, pues no sólo muestra una falta de respeto, sino que puede infligir una herida que llega a causar en sus víctimas un mutilador odio a sí mismas. Odio hacia sí mismo que Axel Honneth ${ }^{3}$ ha expresado en el primer tipo de los agravios morales: un maltrato que arrebata a un sujeto la seguridad de poder disponer de su bienestar, al destruir la confianza en sí mismo, es decir, en su valor como persona. Lo que en buena parte les sucede a los mestizos que no se atreven a reconocer sus orígenes indígenas.

La causa típica de esta herida moral, amén de sus reincidencias en el maltrato físico, la tortura y la violación, es la reificación. Como muestra de ella tenemos las Cartas de relación de Hernán Cortés donde a los indios se les llama «perros» y también «bárbaros» susceptibles de llegar a ser «esclavos» ${ }^{4}$. Los expertos coinciden que la peor campaña de desprestigio hacia los indios la iniciaron desde 1524 los dominicos Tomás Ortiz y Domingo de Bentanzos, este último se expresó así: «El juicio y sentencia de Dios justísimamente es dado sobre ellos, que todos mueran y no quede dellos [sic] memoria porque sus pecados tan horribles y contra toda natura cual nunca jamás se ha hallado [...]. Tengo por muy cierto y averiguado que todos los indios se han de acabar y consumir todos muy presto» $\aleph^{5}$. Esclavitud y servidumbre, si no es que la muerte, era el mejor destino de los naturales que no se alinearon como vasallos del emperador Carlos V. Estas condiciones de cosificación desarrollan en los sujetos una especie de vergüenza social que les impide conducirse con autonomía, perdiendo la seguridad en sí mismos, lo que a la postre algunos expresan con la frase: «se comporta como un indio». Baste consultar la

${ }^{2}$ CH. TAYLOR, El multiculturalismo y la política del reconocimiento, México, FCE, 1993.

3 A. HONNETH, «Reconocimiento y obligaciones morales» en Revista Internacional de Filosofía Política (8), Alemania, 1996.

${ }^{4}$ H. CORTÉS, Cartas de relación de la conquista de América, México, Ed. Nueva España, 1940.

${ }^{5}$ Memorial de fray domingo de Betanzos al Consejo de Indias, 1536, agi, Indiferente General, 1524, citado por M. LEÓN-PORTILLA en El indio vivo visto por los frailes en el siglo XVI, Recuperado de http://www.historicas.unam.mx/publicaciones/revistas/nahuatl/pdf/ecn41/851.pdf, recuperado el 12 de octubre de 2012. 
entrada «indio» en la versión actual del Diccionario de la Real Academia Española de la Lengua para apercibir el uso despectivo, instrumental, de engaño, de vergüenza y desacierto o perjudicial.

El indio fue visto como maligno, Sahagún describe en su monumental obra que antes de la llegada de los españoles al territorio americano: «Todo era antaño tiniebla y engaño. Era el mexicano pueblo esclavo, dominio propio de su peor enemigo, [dado que] el indio era en su gentilidad enemigo de Dios y digno, por ende del mayor castigo, porque aborrece Dios a los idólatras» ${ }^{6}$. Así, la posibilidad de evangelización y vasallaje llevó las cosas hasta la célebre Junta de Valladolid, en 1551, donde se discutió el reconocimiento que como humanos los indios deberían tener para ser educados y liberarlos de la idolatría y de la costumbre de los sacrificios humanos. Pero el falso reconocimiento ya había operado sus efectos, porque el proyecto de la evangelización cristiana fue fraudulento. Zorrilla relata que desde 1503 Nicolás de Ovando y otros colonizadores se las ingeniaron para que la reina Isabel decretara que los indios deberían trabajar con los españoles, a cambio de un jornal, con la principal misión de tener una convivencia evangelizadora. Pero la realidad es que no hubo paga alguna, y todavía peor, se reclutaron para el trabajo forzado a niños, mujeres y familias enteras. De modo que las encomiendas isabelinas no superaron el estado de injusticia del repartimiento de indios colombinos ${ }^{7}$. La misma piedad de la reina delata la visión eurocéntrica con que trató a las culturas indígenas como infieles y salvajes, pues la encomienda tenía como misión la evangelización. Las legislaciones, los sistemas y las ideologías en las cuales los gobiernos de la Colonia se hallaban constituidos también apoyaron dicha cosificación. Si bien es cierto que la Corona emitió en el siglo XVI una legislación proteccionista, paralela a la bula Sublimi Deus dada por el papa Paulo III en 1537, con lo cual se evitó que los indígenas fueran exterminados (a excepción de la región caribeña), en opinión de Jesús María Serna Moreno, «ninguna de estas normas tenía como propósito impedir la explotación del indígena, sino reglamentarla y racionalizarla» ${ }^{8}$. Es decir, ya fuera por la vía de la explotación o de la evangelización forzada, los indios fueron reificados.

\footnotetext{
${ }^{6}$ B. DE SAHAGÚN, Historia general de las cosas de Nueva España, México, Ed. Nueva España, 1946.

7 V. ZORRILLA, El estado de naturaleza en Bartolomé de las Casas, España: Servicio de publicaciones de la Universidad de Navarra, 2012.

8 J. Serna, «Indigenistas, Políticas», en Diccionario de Filosofia Latinoamericana, Cerutti et alia (ed.), México, Universidad Autónoma del Estado de México, 2000.
} 
Revisemos algunas de estas formas graves de «inculturación o civilización» reificante. La cosmovisión europea que se impuso en la Colonia arrastra una raíz aristotélico-tomista que, como en toda posibilidad, pudiendo ser bien utilizada no lo fue. Aristóteles había asentado una afirmación que quedaría para la posteridad como argumento de autoridad: «Es también por necesidad, por razones de seguridad, la unión entre los que por naturaleza deben respectivamente mandar y obedecer (Quien por su inteligencia es capaz de previsión, es por naturaleza gobernante y por naturaleza señor, al paso que quien es capaz con su cuerpo de ejecutar aquellas providencias, es súbdito y esclavo por naturaleza...»" Así por naturaleza se supone que unos deben gobernar y otros ser esclavos. Santo Tomás de Aquino, siguiendo a Aristóteles y aunando argumentos de su autoría en el contexto cristiano también asentó: «en cuanto que lo propio del siervo es ser movido por el imperio del señor $\rangle^{10}$, con lo cual dio pauta para deducir que algunos individuos deben ser vasallos y habrán de obedecer siempre a otros, quiénes serán sus amos. Y quizá podría hacerse apología del argumento aquinate señalando que los términos «siervo»y «señon» son utilizados en sentido metafórico, asignando para los primeros las creaturas y para el segundo a cualquier sujeto intelectual (a excepción de Dios, en cuyo caso debería nombrarse con inicial mayúscula o referírsele tal cual como Dios, de la manera que acontece en otras líneas del mismo texto). Sin embargo, más allá de la sospecha metafórica, en la Suma Contra Gentiles el doctor angélico establece: «Luego toda otra creatura está sujeta a servidumbre, y sólo es libre la naturaleza intelectual. Pero en todo régimen se tiene cuidado de los seres libres por sí mismos» ${ }^{11}$. Afirmación con la cual se refuerza el antecedente reificante: quiénes merecen gobernar tienen tal mérito porque se guían por la inteligencia que debe gobernar a las pasiones, la ira, la sensualidad, etc.; y quiénes deben obedecer han de hacerlo porque su naturaleza se inclina por las tendencias irracionales a las que está sujeta su alma. Los primeros, ya en la era cristiana, conocen a Dios en su trinitaria personalidad, mientras que los segundos, que lo desconocen, deben seguir y obedecer a los primeros. Los indios americanos, por razones obvias, no conocían al Dios cristiano y trinitario y, por tanto, deberían obedecer a quiénes si lo conocen.

\footnotetext{
9 Aristóteles, Política, México: Universidad Nacional Autónoma de México, 2000.

${ }^{10}$ T. De Aquino, Suma de Teología, Vol. v, Madrid: Biblioteca de Autores Cristianos, 2002.

${ }_{11}$ T. De Aquino, Suma contra los gentiles, México, Ed. Porrúa, S.A, 1977.
} 
Para la mentalidad europea en la época de la Conquista, el papa es el cristiano que más y mejor conoce a Dios. Por tanto, todos los indios han de quedar bajo la jurisdicción del papa y éste, por intermediación de los nobles y sus capataces, extiende su dominio de manera temporal e indirecta. Esta es, al decir verdad sin muchos matices, la posición que encontramos en el Tratado comprobatorio del Imperio soberano y principado universal que los Reyes de Castilla y de León tienen sobre las Indias (1552) de Bartolomé de las Casas (el subrayado de «universal» es nuestro y nos lo permitimos en aras de ejemplificar la pretensión de universalidad de la visión de la época, así como la supuesta superioridad que la universalidad por sí misma tendría, cuestión por demás debatible). Los cristianos y los emperadores cristianos, luego entonces, tienen el derecho de evangelizar, defenderse de quiénes lo impidan y utilizar todos los medios a su alcance para lograr esta labor trascendental. Incluso la dominación, conquista y despojo de los indios, pues ello les proveería de más medios para evangelizar. Tales son los argumentos generales de Fray Alonso de la Veracruz en De dominio infidelium et iusto bello (entre 1553 y 1556) y Relectio de decimis (entre 1555 y 1557). Y todavía una versión más severa de la cosificación que sufrieron los indios la encontramos en las argumentaciones de Domingo de Soto. El fraile del blanco hábito alega, citando al pasaje aristotélico que hemos referido, que «entre el siervo y su señor no se puede dar absolutamente lo justo... así como entre el instrumento y quien lo maneja no hay propiamente razón de lo justo, ni constituye injuria alguna para el instrumento que quien lo maneja haga uso de él a su gusto, así también ocurre entre el siervo y su señor» ${ }^{12}$. El texto habla por sí mismo, no sólo el indio es considerado siervo, sino el siervo no tiene relación alguna de igualdad con el amo y por ello pude ser utilizado a placer, es decir, queda completamente cosificado, aún más allá de la analogía de proporcionalidad que lo compara con un instrumento.

Pero lo asombroso apenas se patentiza: los tres autores referidos anteriormente eran teólogos y enfrentaban al «humanista» Juan Ginés de Sepúlveda quién, en un tratado censurado en el reino español (Democrates, sive de justi belli causis) y en otra polémica obra (De justis belli causis apud indios) argumentaba que existían justas y bellas causas para hacer la guerra contra los indios. Categóricamente escribe: «Con perfecto derecho los españoles imperan sobre estos bárbaros del Nuevo Mundo e islas adyacentes, los cuales en prudencia, ingenio, virtud y humanidad son tan inferiores a los españoles como niños a

12 D. DE SOTO, De iustitia et iure, Madrid, Instituto de Estudios Políticos, 1967-1968. 
los adultos y las mujeres a los varones, habiendo entre ellos tanta diferencia como la que va de gentes fieras y crueles a gentes clementísimas» ${ }^{13}$. Las analogías de Sepúlveda sólo pueden entenderse en el contexto de la época; pues iguala a los indios con la barbarie y a ésta con los niños, las mujeres y la crueldad. Sin duda, la reificación del indio era imposible de evitar cuando desde los prejuicios y la carencia de evidencias, niños y mujeres eran considerados de manera natural y por sus naturalezas mismas despreciables. Pero, la verdadera razón para someter culturalmente a indios, niños y mujeres no reside en sus semejanzas, sino que, según Sepúlveda se justifica porque: «La primera [razón justa de la guerra de conquista] es que siendo por naturaleza bárbaros, incultos e inhumanos, se niegan a admitir el imperio de los que son más prudentes, poderosos y perfectos que ellos; imperio que les traería grandísimas utilidades, magnas comodidades, siendo además cosa justa por derecho natural que la materia obedezca a la forma» ${ }^{14}$. Y aún todavía peor, en el Dermócrates alter (una de las versiones censuradas) Sepúlveda consideró «que las personas y los bienes de los que hayan sido vencidos en justa guerra pasan a poder de los vencedores» ${ }^{15}$. Es decir, las personas de los indios eran consideradas botines de guerra. La cosificación se hace extrema y la única pequeña diferencia entre este autor y sus teólogos opositores es la distancia entre oprimir o cristianizar forzadamente.

El pensamiento filosófico y teológico sobre los indios en los siglos XV y XVI presenta una franca falta de reconocimiento al sentido de pertenencia y tradición de los indígenas; éstos son alienados en un proyecto de Historia de corte típicamente eurocéntrico: único, lineal y progresivo. Es decir, por la narrativa del exclusivo megarelato cristiano occidental, con un marcado sentido teleológico tensionado por un modelo desarrollista y salvífico. Si bien ello es comprensible por las limitaciones, creencias e intereses de la época, lo inexcusable es que estas ideas reificantes y eurocéntricas se extendieron soterradamente hasta el siglo XX en casi toda América latina. Santiago Castro Gómez relata como en el siglo XX Walter Mignolo apunta la reacción del «giro epistemológico» en él mismo y en pensadores como Prebisch, Ribeiro, Kusch, Dussel y otros para acabar con el concepto eurocéntrico de la Red Interamericana de Estudios Culturales financiada por la fundación Rockefeller ${ }^{16}$. América latina padeció la consigna

${ }^{13}$ J. GINÉS, Tratado sobre las justas causas de la guerra contra los indios, México, F.C.E., 1941.

${ }^{14} \mathrm{~J}$. GINÉS, Tratado sobre las justas causas de la guerra contra los indios, 153.

15 J. GINÉS, Demócrates alter, Matriti, Opera, vol IV, 1780.

16 S. CASTRO, «Poscolonialismo», Diccionario de Filosofía Latinoamericana, 279-280. 
de políticas nacionales y estatales para construir una identidad cultural encausada a «realizar la patria» en orden a un modelo europeo de progreso. Para ello resultó imprescindible discriminar qué población era indígena para considerarla fuera de las estadísticas del progreso y hacerlas objeto de los programas de desarrollo del modelo Estatal. Pero los indígenas son de muchas etnias y características (con sólo pensar en una población sedentaria y una nómada surge el error de clasificar en una misma cultura a identidades diferentes o de dividir cualidades similares en taxonomías distintas). En un trabajo antropológico Frye ${ }^{17}$ hace ver que los estudiosos y muchos de los encargados de tomar decisiones gubernamentales emplean la denominación «indio» de manera ambigua, «como adjetivo, sustantivo, condición y esencia». Ello da idea de la reificación actual de la que todavía son objeto los indígenas. Para muchas personas «indígena» simplemente significa pobre, inculto, mugroso o atrasado. Amén de que durante la Colonia implicaba flojo, lascivo, desobligado y traicionero.

Desgraciadamente cuando un error entra en la Historia es muy difícil de extirpar, según una expresión atribuida al controvertido historiador Jacques Le Goff. No obstante, los efectos de estos ejemplos nos advierten: las consideraciones eurocéntricas han querido transformar a los indígenas o indios actuales en cristianos mestizos por razones hegemónicas que destruyen las identidades culturales no alineadas. Parafraseando al gran antropólogo Robichaux ${ }^{18}$ podemos decir que desde la Conquista de América se ha querido colocar al indio indomable en los museos y al útil en la parroquia del mestizaje. Porque un efecto de la Historia eurocéntrica es considerar al «mestizaje» como un paso evolutivo en la historia indígena.

Desde esta óptica los mestizos tienen razón para negar sus raíces y querer diferenciarse. Sin embargo, cuando lo indígena se ve como el lugar original desde donde se devela la «americanidad», surge «la paradoja del indigenismo» ${ }^{19}$; se propicia la negación de lo indígena y hasta de lo mestizo, pero no pueden omitirse para la constitución de lo latinoamericano. Ello obliga a la filosofía a preguntarse por la identidad, la tradición, a respetar la historia de la pluralidad étnica y evitar taxonomías reificantes y esencialistas.

${ }^{17}$ D. FRYE, Indians into Mexicans: History and identity in a Mexican town, Austin, University of Texas Press, 1996.

${ }^{18}$ D. ROBICHAUX, Identidades indefinidas: entre «indio» y «mestizo» en México y América Latina, 2007.

${ }^{19}$ L. VILLORO, Los grandes momentos del indigenismo en México, 235. 
Los «mestizos» latinoamericanos deben responder ¿cómo salir de la paradoja y llegar a ser sí mismos?

\section{La interpretación de lo ajeno desde lo propio y su apropiación}

La filosofía de la comprensión o metodología hermenéutica es reconocida por Taylor (uno de los mayores promotores de las políticas multiculturales y del reconocimiento) como el proceso por el cual una cultura ajena puede ser comprendida. El autor canadiense indica: «Lo que tiene que ocurrir es lo que Gadamer denomina la "fusión de horizontes" ${ }^{20}$. Por ello, la hermenéutica es la condición para solucionar los problemas de la reificación india en el sentido de lograr un verdadero reconocimiento que aporte respuestas políticas, jurídicas, psicológicas o sociales. No es la tolerancia, como ya se ha evaluado $^{21}$, ni el simple respeto, -jurídicamente correcto pero personalmente indiferente-, a los Derechos Humanos fundamentales, las propuestas más viables, sino el reconocimiento verdadero que transforma tanto al sujeto que reconoce como al reconocido. De ahí la relevancia, vanguardia y vigencia que tiene la temática del reconocimiento hoy en día, como puede percatarse no sólo por la vitalización que le dan figuras como Ricoeur y Honneth, sino por la amplitud, alcances y aplicaciones que muestra el desarrollo que tiene en el http://www.recognitionforum.com.au/. Sin auténtico reconocimiento no habrá pluralidad étnico-civilizatoria, sólo enfrentamientos o indiferencia.

Asumir el lugar de la propia visión. Tanto las comunidades como los sujetos cuentan con su horizonte de significatividad. Es decir, al pertenecer a un contexto histórico y una tradición específicos, que se conserva y transmite por su lenguaje, poseen una serie de pre-juicios. Éstos no deben condenarse siempre como actitudes reprobables, sino comprenderse como modos anticipados de ver, sentir, pensar y actuar en el mundo. La hermenéutica no denota a los prejuicios con la evaluación negativa que les atribuyó la Ilustración desde Bacon, sino que, por el contrario, los valora como un núcleo que nos ayuda a comprender la cosmovisión cultural de quién mira, pues los considera como «...

${ }^{20} \mathrm{CH}$. TAYLOR, El multiculturalismo y la política del reconocimiento, 99.

21 J. AGUIRRE, "Hermeneutic contributions to the citizen proyect», Archiv für Rechts- und Socialphilosophie, 98 (4), 2012. 
[el] juicio que se forma antes de la convalidación definitiva de todos los momentos que son objetivamente determinantes» ${ }^{22}$. Dicho en otras palabras, no es un juicio carente de fundamento y por tanto falso, sino un juicio con capacidad de ser valorado. Los prejuicios son los lentes por los que mira y se constituye una tradición y lo que ha formado a un sujeto. Y por tanto, son la clave para descubrir qué y por qué algo es significativo en una cultura. Son la realidad histórica del ser 23

Los prejuicios, instalados de manera previa a toda experiencia de mundo y su correspondiente interpretación, son la pre-estructura de la comprensión. Sólo se pueden mostrar por medio de la autorreflexión o ante el choque y enfrentamiento con algo que haga salir al sujeto de sus parámetros porque se le presenta como «ajeno». En la situación ante lo «anómalo», el sujeto ha de descubrir en sí mismo algo extraño: al sacar a la luz su posesión de prejuicios y hacer autoconciencia de las gafas con las que interpreta el mundo, se encuentra con su propio horizonte de significados.

Si el horizonte es «(...) el ámbito de visión que abarca y encierra todo lo que es visible desde un determinado punto» ${ }^{24}$. «el horizonte de significados u horizonte de la historia efectual, es lo que se configura al tiempo que en reciprocidad configura al sujeto. Por lo tanto, el horizonte de significatividad no es fijo, sino que se encuentra en perpetuo movimiento». ${ }^{25}$ Es como si dijéramos: los intereses determinan lo que hay que ver y a su vez, lo visto, recrea a los intereses. Así, el horizonte de significados, al no ser inmóvil, permite al sujeto percatarse de ser un ser inacabado, en constante cambio y crecimiento. El que no tiene un reconocimiento de su propio horizonte simplemente no se ve lo suficiente y por tanto sólo es capaz de valorar lo demás como extraño sin poder valorar, a su vez, el proceso de la valoración que hace. Sólo ve aquello que le cae más cerca. Este sería el caso de los ejemplos que reifican a los indígenas y mestizos. Simplemente no se comprende lo ajeno. Lo que está más allá de sus límites sin ver sus límites, se le limita a parámetros próximos. Pero no se logra la aplicación de los propios parámetros sobre su propia indagatoria. Seguramente esto le aconteció a Ortiz, Betanzos, Ginés de Sepúlveda y muchos otros. En contraste, quien tiene el reconocimiento de los propios prejuicios, tiene

\footnotetext{
22 H. GADAMER, Verdady Método I, España, Ediciones Sígueme-Salamanca, 2000.

${ }^{23}$ H. GADAMER, Verdad y Método I, 334.

${ }^{24}$ H. GADAMER, Verdady Método I, 372.

${ }^{25}$ H. GADAMER, Verdady Método I, 337.
} 
la capacidad de poder ver por encima de los mismos y por tanto, valorar correctamente lo que cae dentro de sus parámetros, tanto de cerca como de lejos, o lo más importante: también «desde dentro», pues está consciente de que hay algo de él que puede ver, al ver aquello que fuera de sí puede ver. El horizonte es el marco de dicha comprensión histórica como significativa ${ }^{26}$. Para dejar claro qué abarca y hacer conciencia de la pertenencia recíproca (pues el sujeto lo posee en la misma medida que el horizonte posee al sujeto, o en palabras de Merleau-Ponty: el perceptor percipiente), es menester reparar en cuatro aspectos preponderantes: a) el sujeto con tradición; b) el sujeto con historia; c) el sujeto con lenguaje y; d) el sujeto que interpreta.

a) La tradición o cultura está constituida por una serie de creencias comunes sostenidas por una colectividad de individuos. «La tradición vendrá a ser la serie de valores compartidos, la forma de vida semejante en colectividad, así como sus comportamientos, costumbres y reglas de conducta en general» ${ }^{27}$. Gadamer por su parte sostiene que lo consagrado por la tradición vendrá a poseer una autoridad. Y aunque ésta sea anónima, determina a las personas, pues tiene poder sobre la acción y el comportamiento $^{28}$. Se constituye en un verdadero elemento fundacional: ejerce acción y comportamiento, es decir, es dinámica en el sujeto, pues al desenvolverse en el sujeto éste desenvuelve su tradición y éste desenvolvimiento a su vez desenvuelve al sujeto.

Entonces es la tradición el medio por el cual se posibilita la autoconciencia, más que como acción, como contenido a conocer y comprender. Se descubre, a vez, que es límite del horizonte y medida por la cual se juzga el entorno que envuelve al sujeto. Afirma Hernández-Pacheco: «Lo que cada uno somos está dado como algo desde dónde se explica nuestra vida y... [es] el presupuesto de toda explicación. Por ello la autoconciencia está históricamente condicionada, y tiene un límite insuperable en la tradición» ${ }^{29}$.

b) El sujeto como historia muestra que el presente nunca se podrá desligar enteramente del pasado. La historia pasada produce la historia del presente, y de ahí atribuimos la tradición. Constantemente se hace revisión histórica, pues más que

\footnotetext{
26 H. GADAMER, Verdady Método I, 337.

27 L. VILLORO, Los grandes momentos del indigenismo en México, 110-111.

${ }^{28}$ H. GADAMER, Verdad y Método I, 348.

29 J. HERNANDEZ-PACHECO, Corrientes Actuales de Filosofía: La Escuela de Francfort, la filosofía bermenéutica, España, Tecnos, 1996.
} 
pertenecernos le pertenecemos a ella ${ }^{30}$. No llegamos a un mundo listo para ser inventado por nosotros, sino que llegamos a un mundo ya hecho por la historia. Pero terminamos de hacer el contexto al cual pertenecemos y nos vemos inmersos en él mucho antes de comprendernos a nosotros mismos por medio de la reflexión. La historia nos determina, pues sus efectos nos constituyen al recaer sobre nuestra propia forma de comprender y de reflexionar el mundo.

Se trata por tanto, al ser sujeto histórico, de descubrir los propios prejuicios que la historia nos ha instaurado. Se trata de realizar la comprensión desde una conciencia histórica, de forma que al detectar lo «históricamente diferente» no nos limitemos a una confirmación de las propias hipótesis referentes a la realidad dada ${ }^{31}$ sino que por el contrario, dejemos que la conciencia histórica nos abra la posibilidad de realizar una auténtica comprensión. Lo que enriquecerá el propio horizonte histórico, al reconocerlo como horizonte de significados.

c) En un principio el lenguaje ejerce influencia en nuestro pensamiento, pues pensamos con palabras. El sujeto como lenguaje posee un logos, una decodificación del mundo que permite pensarlo; pero a su vez es un logos que puede comunicar, que puede transmitir conocimiento a través del diálogo.

La socialización es por una parte la maduración de la conducta social. Sin embargo, es también el aprendizaje de un lenguaje, de la palabra hablada. Lenguaje que es a su vez, al ser aprehendido, aceptación de compromisos y de ideologías. El aprendizaje del habla es un constante ejercicio de expresiones y de temas, pero también es nuestra formación de creencias y de opiniones. El lenguaje es el camino en el cual se mueve, una estructura preformada de articulaciones significativas ${ }^{32}$. Por lo que sería más correcto afirmar que el lenguaje nos habla, a decir que nosotros lo hablamos a él ${ }^{33}$.

Sin embargo, no ha de concebirse a la experiencia lingüística, ni siquiera a la historia o a la tradición, como lo que meramente determinan al sujeto y las comunidades. Porque, como hemos visto en el caso sobre los indígenas, una o varias de estas categorías combinadas, de todos modos los reificarán. Por lo contrario, ha de concebirse una seria participación del sujeto en la creación del lenguaje a partir de su pragmática, y a su vez, en

\footnotetext{
${ }^{30}$ H. GADAMER, Verdad y Método I, 344.

${ }^{31}$ H. GADAMER, Verdady Método I, 64.

32 H. GADAMER, Verdad y Método I, 197.

33 J. HERNANDEZ-PACHECO, Corrientes Actuales de Filosofia, 251
} 
la generación de su historia y la conservación o transformación de su tradición. Y estas acciones implican al proceso de la interpretación para lograr producir un sentido, una significatividad, un puesto desde donde se generarán los supuestos, lo que se supondrá, precisamente; el lenguaje, la Historia y la tradición de un individuo, comunidad o cultura.

d) Con lo anterior se arriba a la necesidad del sujeto que interpreta; los seres humanos, al auto-concebirse como seres interpretadores, ya no sólo proyectarán sus prejuicios en todo suceso ajeno, sino que se expondrán en ellos. Ricoeur lo manifiesta diciendo: «recibo del acto de apropiación lo que el mundo de la interpretación me propone, un sí (de mî) más amplio» ${ }^{34}$. No se trata de desligarse de los prejuicios propios, ya que estos son parte de la propia tradición, historia y lenguaje. Se trata de hacer autoconciencia de ellos para quitarles el título de «única verdad». De hecho, debemos mantenerlos, pero conscientemente, para no buscar en lo ajeno lo igual y a su vez encontrar en la diferencia la mismidad ontológica. Para ello tendremos que pasar al segundo paso.

Provocar la perspectiva histórica. Como cada sujeto es parte de un conjunto de tradiciones y responde al interés de una época histórica en la cual se encuentra sumergido, entonces debemos comprender al otro desde esa perspectiva, pero sobre todo a nosotros mismos desde nuestro interés y nuestra historicidad.

Ahora bien, ¿qué es cabalmente la comprensión de la pluralidad indoamericana por encima de la mera explicación o entendimiento? En primer lugar la comprensión se da por la dinamicidad de dos movimientos: el movimiento de la tradición y el movimiento del intérprete. El primero es evidente desde la anticipación del sentido que guía nuestra manera de ver, sentir, pensar y actuar en el mundo, y no es un mero producto de la subjetividad, sino que se determina desde la comunidad, la cual, precisamente nos une a la tradición. Esto es lo que principalmente debería comprenderse no sólo para el caso indomericano, sino para todo escenario plural, amén de que esta relación entre individuo y tradición está sometida a un proceso de continua formación. «No es un simple presupuesto bajo el cual nos encontramos siempre, sino que nosotros mismos la instauramos en tanto comprendemos y participamos del acontecer de la tradición» ${ }^{35}$. He

\footnotetext{
${ }^{34}$ P. RICOEUR, Del texto a la acción. Ensayos de Hermenéutica II, México, FCE, 2002.

35 H. GADAMER, Verdady Método I, 363.
} 
aquí el inicio del segundo movimiento: sostenerse en esa tradición y poder hacerlo a cierta distancia que no ciegue la percepción desde la cual se sabe percibiendo. Por lo tanto, debemos respetar y mantener la serie de supuestos que marcarán la diferencia entre ambos interlocutores. Eso sería respetar la tradición y la identidad cultural de los otros.

La diferencia entre interlocutores podemos visualizarla como «diferencia histórica». Por lo que «(...) se trata de reconocer la distancia en el tiempo como una posibilidad positiva y productiva del comprender» ${ }^{36}$. Esta «diferencia histórica», en el caso de dos individuos que ante un panorama multicultural necesitan comprenderse a partir del choque de horizontes, se toma como la distancia en la que el intérprete se presta a desligarse de sus prejuicios y no pretende desligar al otro de los suyos al interpretarlo desde sus propios parámetros o dialogar con él. De lo contrario, estaríamos provocando un discurso monológico como el de la Colonia y la conquista señaladas arriba, en el cual, si bien los primeros evangelizadores defendieron la dignidad humana del indio, a su vez no comprendieron su propia religiosidad. Pues fue tardíamente cuando aprendieron a aprovecharla, pero siempre bajo el interés de inculturizar el cristianismo. La diferencia o distancia histórica se realiza al saberse poseedor de un horizonte de significados propios, mientras además se reconoce que el otro responde a su propio horizonte de significados. De esta manera mantenemos nuestros prejuicios de modo consciente, reconociendo que existen otros horizontes de significatividad y que por lo tanto, nuestros parámetros le resultarán «lo ajeno, lo otro» al Otro. Así podemos descubrirnos siendo el otro del Otro. Es decir, nos excluimos de la única manera de ver, sentir, pensar y hacer en el mundo, y a su vez, nos implicamos en una actitud ética ante los demás.

Cuando se hace distancia, se encuentra el verdadero sentido de las cosas. Ya que gracias a ella es posible «resolver la verdadera cuestión crítica de la hermenéutica, la de distinguir los prejuicios verdaderos bajo los cuales comprendemos, de los prejuicios falsos que producen malentendidos $»^{37}$. La tarea consiste en hacer conciencia histórica, hacer conciencia de los propios prejuicios que guían la comprensión, con el fin de que la tradición se destaque como opinión y no como criterio último de verdad. Es decir, se ha de poner en suspenso la validez del propio parecer. Un verdadero acto fenomenológico

${ }^{36}$ H. GADAMER, Verdady Método I, 367. 
de la «epojé» que, al inicio de toda hermenéutica, exigía Husserl. Cuanto más importante en el momento en que algo nos interpela.

La conciencia de los propios prejuicios ante el otro, el distanciamiento de sí al reconocer las diferencias, es la experiencia hermenéutica. Ésta posibilita la solución al choque de cosmovisiones porque, reconocidos los correspondientes horizontes de significatividad, están dadas las condiciones para obtener la fusión de horizontes. Nos atrevemos a decir que los sabios «Tlamatinime» indígenas y los padres franciscanos, encabezados por Martín de Valencia, dieron una muestra eficaz de este ejercicio, según puede recogerse en El coloquio de los doce (acontecido en 1524), que años después consignó Sahagún ${ }^{38}$. La conversión hacia los indios se logró alegando que, según su propio modo guerrero de pensar y de actuar, tiene mejor ejército, y por tanto, mejor Dios para ser aceptado, aquél que logra vencer a los demás. Y habiendo vencido los españoles a los aztecas, éstos aceptaron que el Dios español debe aceptarse, del mismo modo que los demás pueblos indios conquistados por los aztecas habían aceptado a los dioses de éstos. En definitiva, los padres franciscanos expusieron sus razones, pero lo hicieron en términos de guerra-conquista-protección divina que poseían sus interlocutores aztecas para provocar la producción de sentido desde el horizonte del otro, del interlocutor. Es decir, comprendieron desde dentro de la cosmovisión azteca el modo de argumentar persuasivamente una verdad que, de suyo, era totalmente ajena al mundo indígena.

Asumir la identidad desde las diferencias. Ante la confrontación con un «otro», aparecen las diferencias. Diferencias de las cuales se obtiene experiencia al develar otro horizonte distinto del propio y provocar la develación del propio. En esa experiencia descubrimos algo de nosotros mismos; descubrimiento que no vendrá a ser unilateral, sino que provocará una transformación al ampliar los respectivos horizontes porque nos comprendemos diferentes ante y desde los otros. Los padres franciscanos del Coloquio de 1524 comprendieron de sí mismos la primacía de sus argumentos de piedad y caridad, al tiempo que se percataron de un interlocutor que le daba primacía al argumento de la fuerza. Y por la develación de los dos horizontes históricos pudieron exponer y adaptar el propio al diferente para que el diferente obtuviera el sentido de la verdad del propio. En el

\footnotetext{
${ }^{38}$ La edición crítica es: Coloquios y doctrina cristiana (Diálogos de 1524 dispuestos por Fray Bernardino de Sahagún), ed. facsimilar, introducción, paleografía, versión del náhuatl y notas de Miguel León-Portilla, Instituto de Investigaciones Históricas, Facsímiles de lingüística y filosofía nahuas, 4, Universidad Nacional Autónoma de México/Fundación de Investigaciones Sociales, A.C., México, 1986.
} 
mundo multicultural no cabe disputar cuál sería la verdad o cuál de las dos culturas estaba en lo correcto, sino lograr la producción de sentido que nos lleve a la comprensión del otro desde sí mismo.

La fusión de horizontes además exige otros factores: entre ellos los del auténtico reconocimiento de diferencias. Charles Taylor ha insistido que el reconocimiento de las diferencias está condicionado por el de las identidades ${ }^{39}$. Si no existe un reconocimiento y aprecio de las identidades ajenas, no podrá existir la valoración de las diferencias. Y la identidad, afirma Taylor, se moldea en parte por el reconocimiento o por la falta de éste. El falso reconocimiento de un individuo o de un grupo de personas puede ser causa de verdaderos daños en la formación de sus identidades, tal como el desarrollo de un reflejo despreciable, degradante o limitativo de uno mismo. Sobre este punto, la insistencia de Taylor ha sido menor a la de Honneth. Al menos así lo expresa Honneth cuando afirma: «En el caso de Taylor el asunto es más complicado, ya que él utilizó el concepto de reconocimiento sólo para el reconocimiento de diferencias... Hegel habla del ser reconocido y del reconocimiento siempre en relación con la idea de igualdad, y eso lo abandona totalmente Taylor en su libro sobre la política del reconocimiento, lo cual, debo decir, me irrita bastante» ${ }^{40}$. Finalmente, el nexo entre identidad y reconocimiento es debido a que la formación de una identidad no se puede dar de manera plenamente individual, porque siempre requeriremos del reconocimiento de otros para afirmarnos como seres individuales y auténticos. Y ello implica la igualdad. Ante la reificación indoamericana se debe proceder con precisión: reconocer la igualdad no es la identificación, pues los seres de distintas etnias, culturas o tradiciones son iguales pero no son idénticos. Por ello la hermenéutica ha de ser dialógica: pues «siempre definimos nuestra identidad en diálogo con las cosas que nuestros otros significantes desean ver en nosotros, y a veces en lucha con ellas» ${ }^{41}$. La necesidad de la lucha se da porque la igualdad no es la asimilación ni la identificación con el otro.

Sin embargo, Gadamer advierte que el verdadero diálogo no consta del simple propósito de llegar a conocer a un individuo, esto es, de formarnos una idea de su posición y posesión de horizonte. Pues esta situación no afectaría necesariamente a

\footnotetext{
${ }^{39} \mathrm{CH}$. TAYLOR, El multiculturalismo y la politica del reconocimiento, 43.

40 A. HONNETH, Reconocimiento y menosprecio, España, Ed. Safekat, 2010.

${ }^{41} \mathrm{CH}$. TAYLOR, El multiculturalismo y la politica del reconocimiento, 53.
} 
ninguno de ambos interlocutores. «Se requiere de «desplazarse» con nuestro propio horizonte hacia el horizonte del otro. Permitiendo de esta forma una auténtica comprensión del otro, al hacerme consciente de su alteridad, de su individualidad irreductible, pues uno es el que desplaza a su situación. El desplazamiento implicará el ascenso a una generalidad superior, al rebasar tanto la peculiaridad propia como la del otro» ${ }^{42}$.

«Desplazarse» a través del diálogo, va más allá de conocer al otro como un objeto de indagación, de entablar una conversación para simplemente entender al interlocutor o superar con acuerdos las diferencias; en palabras un tanto existencialistas podríamos decir: «es un comprender lo que es diferente de mí en ti y no las diferencias de ti que se hacen patentes en mí». Así, comprender no significa dar cuenta «de un objeto de indagación» para predecir su comportamiento, sino, parafraseando a Taylor, es más bien una actitud donde nunca se cierra el paso a lo que el otro tiene que decir. Conocer es pretender controlar intelectualmente al objeto, haciendo imposible que éste responda; mientras comprender es establecer al otro sobre el diálogo 43 .

En el diálogo para llevar a cabo la fusión de los horizontes no sólo se comprende un objeto, sino se desea comprenderlo como no objeto, con el propósito justamente de no reificarlo. El diálogo exige la comprensión de alguien que a su vez es capaz de comprendernos. Las expectativas sobre lo otro cambian y se abre camino al descubrimiento. Éste vendrá a ser enriquecedor a partir del logos que se transmite y fusiona a través del diálogo. Palabra, que como enseñó Carlos Lenkersdorf, es dicha en la medida que es escuchada ${ }^{44}$. Pues aceptar un diálogo implica asumir el mundo implícito en su lenguaje. Lenguaje que transmite tradición, contexto, historia y cosmovisión. En el diálogo, el mundo es el suelo común y vendrá a ser la consecuencia y acuerdo de la conversación ${ }^{45}$.

La comprensión y el diálogo preguntan por la tradición del otro, por su horizonte de significados, haciendo epojé del propio. No se pregunta por la identificación, pues sería proyectarse en prejuicios y supuestos, sino por lo diferente, por su identidad. Produciendo, más que un intercambio de información, un encuentro humano. Ahí surge la fusión de los horizontes, en el encuentro ante la identidad y reconocimiento del otro y

\footnotetext{
42 H.GADAMER, Verdad y Método I, 375.

${ }^{43} \mathrm{CH}$. TAYLOR, El multiculturalismo y la politica del reconocimiento, 2002.

${ }^{44}$ C. LENKERSDORF, Filosofar en clave tojolabal. México, Porrúa, 2002.

${ }^{45} \mathrm{~J}$. HERNANDEZ-PACHECO, Corrientes Actuales de Filosofia, 251
} 
su posterior separación. Pues la fusión de horizontes no implica la disolución de identidades en identificaciones enajenantes. Esto último no se comprende del todo en los proyectos de asimilación, integración y desarrollo de identidades hacia una nación de modelo eurocéntrico sobre las «naciones» indoamericanas que no fueron, ni son, y por lo que parece ni quisieron, ni quieren ser eurocéntricas.

En el mismo ánimo y con el propósito de que el caso indio y mestizo resulte un modelo ante el resto de la aldea global atravesada por la economía del mercado libre y por las incontenibles migraciones, debemos insistir en utilizar la hermenéutica como una interrogación que en su mismo interpelar interpreta sus propias preguntas la mayoría de las veces a partir de descifrar las respuestas del interlocutor. Con ello permite el diálogo de saberes y establece los puentes entre culturas reconociendo en cada una su identidad insubordinable a proyectos ajenos y dignificándola como única e irrepetible. Actitud altamente deseable no sólo ante la pluralidad étnica de la Colonia, sino también en la circunstancia global multicultural actual.

\section{Discusión sobre el alcance de la filosofía de la comprensión}

No pueden ignorarse algunas críticas a la propuesta de la filosofía de la comprensión. En esta ejemplificación particular sobre la Colonia sin duda falta la especificación en varias áreas: no todas las acciones de colonización fueron reificantes en la misma medida. Algunas de ellas quizá no lo fueron; aunque existe mucha dificultad en encontrar un caso neutro o inocente; quizá el más notable de ellos fue el de las misiones jesuitas en Paraná, Guayrá y la región de los guaycurúes donde quedó abolida la encomienda desde 1608. Por otra parte notables expertos como Beuchot reconocen que aún en los procesos más piadosos se encuentran cosas muy duras ${ }^{46}$. A su vez, no todo el universo colonial e indoamericano es homogéneo histórica y geopolíticamente; es bien sabida la alianza que Cortés estableció con los tlaxcaltecas y la migración forzada de algunas células de esta nación hacia Aridamérica para acercar y exhortar el modelo sedentario a las civilizaciones nómadas. También es sabido que en algunos casos la Colonia liberó de naciones indígenas

\footnotetext{
${ }^{46}$ M. BEUCHOT, Filosofía social de los pensadores novohispanos, México, Instituto Mexicano de Doctrina Social
} Cristiana, 2000. 
guerreras, crueles y hasta antropofágicas a otros pueblos precolombinos que padecían explotación, marginación, violencia y esclavitud. Por ende, no toda la Colonia fue Conquista.

Más allá de la enorme diversidad étnica y social de la época, a cuya amplitud no puede hacerse justicia en un ensayo limitado por el espacio propio de este texto, cabe hacer hincapié en el propio horizonte de la filosofía de la comprensión: la postulación de un sujeto de la tradición, de la historia, del lenguaje y la interpretación caería en una falacia de petición de principio al suponer lo que desea demostrar: que siempre es posible para cualquier sujeto una auténtica comprensión entre culturas. Lo que es posible -y aquí se problematiza- es una comprensión diversa de culturas a las que el sujeto que comprende pertenece. Por supuesto que hubiera sido deseable que la cosmovisión de la Colonia y la Conquista no partieran desde un prejuicio de superioridad y universalidad que resultaron reificantes, pero esa lección nos es valiosa para la comprensión de la multiculturalidad actual. No debemos ver a los sujetos de otras culturas como objetos, ni siquiera es posible garantizar que los sujetos de otras culturas puedan, por principio, visualizarse así mismos como sujetos (por ejemplo las culturas llamadas desde la racionalidad occidental «holísticas» o con cosmovisiones «antropo-morfizantes», que más bien serían «cosmomorfizantes») y menos aún pretender que puedan comprender, a su vez, otros horizontes. En el mismo centro de Europa autores como Benajmín, Derrida, Lyotard, Deleuzze, Guattari y muchas otras como Kristeva, Mitchell, Cixous, han promovido los efectos de la hermenéutica en la post-modernidad como un pensamiento deconstructivo y descentralizador de una única y auténtica idea de sujeto. Afirmar que tanto uno mismo como cualquier otro somos sujetos no es una tesis universal, sino un postulado metodológico para comprender al otro desde sí mismo. El basamento epistemológico de la hermenéutica auxilia al pensamiento post- y meta- colonial cuando, precisamente, desea romper con la pertenencia cegadora (y más vehemente el rompimiento mientras más forzada sea la sujeción) de un sujeto a una tradición, lenguaje o historia inalterables. La denuncia del mega-relato, desde cualesquier meta-relato es lo que permite abandonar las pretensiones de validez y alcanzar las posibilidades de una producción de sentido.

La filosofía de la comprensión busca la producción de sentido muy por encima de la pretensión de verdad universal: esa es la fusión de horizontes de significatividad. Para ello desea obtener el reconocimiento y sus benéficos efectos, pero no condiciona su 
proceder a la existencia o concepción de identidades fijas, a priori o esencialistas. Suponer ello sería, precisamente, caer por el barranco de la reificación del que desea salir.

Siendo congruentes a los principios hermenéuticos mismos no se puede presentar el eurocentrismo como la actitud radicalmente equivocada y a la filosofía de la comprensión como la definitivamente correcta. La filosofía de la comprensión tiene también como obligación comprender desde sí mismo al propio eurocentrismo en sus horizontes de significatividad, sean históricos o actuales.

El eurocentrismo histórico, representado por el pensamiento de colonización, es discutido por las teorías críticas postcoloniales: interpelan la validez de sus juicios universales. La hermenéutica no ha de cometer anacronismos y precisamente la comprensión de los horizontes eurocéntricos y sus consecuentes reificaciones constituyen un reto por asumir. Pero no un proceder a justificar.

El eurocentrismo actual es, sin lugar a dudas, polisémico; puede abarcar desde la lógica transnacional del mercado libre, pasando por la globalización, hasta la sutil enajenación de análisis coloniales y postcoloniales con categorías puestas o impuestas desde la misma perspectiva colonizadora. El debate en la década de los noventas del siglo pasado entre los Culural Studies y el Latin American Subaltern Studies Group, evidencia la insuficiencia categorial, semántica y teórica para encontrar salidas a las herencias de la colonización y postcolonización: la occidentalización forzada, el imperialismo y la opresión. También se hace patente, entonces, la necesidad de la filosofía hermenéutica que afirma como viable la comprensión diversa entre culturas, en la medida que logra el reconocimiento de las diferencias desde las más ajenas diferencias.

Si algún servicio ha hecho la filosofía de la comprensión a la postmodernidad ha sido, precisamente, liberar a la postcolonización de las categorías propias de la colonización. Horkheimer, Adorno y Vattimo, por mencionar sólo algunos, se propusieron una crítica a la razón cuando ésta resultase violenta, coercitiva y genocida. Pero no se trata de la negación de la razón, advierte Mignolo ${ }^{47}$, sino de la afirmación de la razón del otro. Porque la razón y los parámetros de subjetividad y centralidad dependen de los diversos loci de enunciación. El locus de la enunciación diferencial es la razón por la

47 W. MIGNOLO, «La razón postcolonial: herencias coloniales y teorías postcoloniales» en A. del Toro (ed.), Postmodernidad y Postcolonialidad, Madrid, Iberoamericana, 1997, 63 
cual ha de renunciarse al esencialismo, como lo hacen Bhabha, Dussel, Kristeva, Moi y Todorov.

Ahora bien, que la filosofía de la comprensión recurra a autores europeos como Gadamer, Ricoeur o Vattimo; o que proceda de una tradición continental desde Schleiermacher o Dilthey, no significa que tenga taras o pretensiones eurocéntricas soterradas. Objetar la validez hermenéutica porque proviene de una tradición europea es alegar una falacia ad-hominem; como discutir que un varón no puede adoptar una ideología feminista por identificarse genéticamente con su género, o argüir que un joven no debe defender de la injusticia a los ancianos.

Por otra parte, la filosofía de la comprensión no pretende una superioridad o una dogmática universalista; todo lo contrario, acepta las dificultades y resistencias que presenta la fusión de horizontes y asume sus limitaciones. Las dificultades clásicas sobre el problema de la verdad de la interpretación no le son desconocidas y en él reconoce que la tarea hermenéutica enfrenta considerables restricciones. No obstante, intenta superarlas con la obligación de ser genética, dialéctica, heurística y proteica ${ }^{48}$.

\section{Conclusión final}

La filosofía de la comprensión aquí expuesta, o sea una hermenéutica aplicada a la revisión de la inculturación de la Conquista y la Colonia, no sólo muestran las injusticias cometidas a los «indios», sino también la falta de comprensión e injusticia con que se condena a los actores inculturizantes del período de la Colonia a causa de la visión unilateral de su horizonte de significatividad y pertenencia. Así como debemos respetar las identidades indoamericanas, también debemos respetar el horizonte de visión que los colonizadores y evangelizadores poseían en los siglos XVI y XVII. Comprensión que, no obstante, para ambos casos no implica su justificación o aceptación, pues tan detestable resulta una conversión forzada a la religión o a cierta pretendida civilización como la antropofagia innecesaria desde los actuales horizontes de sentido.

Por parte de la hermenéutica misma, se presenta tanto una oportunidad (como ejemplo y modelo en el mundo actual), y también la advertencia de algunas limitaciones.

48 B. LONERGAN, Insight, Salamanca, Ediciones Sígueme, 1999. 
Como oportunidad está la intención del reconocimiento de los horizontes de pertenencia y de significatividad y su fusión. Es decir, la posibilidad de considerar a lo más ajeno y amenazante como otro libre y con capacidades suficientes para revisar su concepción del bien, de actuar con identidad moral, de asumir sus compromisos humanitarios y reclamar hasta la promoción de culturas ajenas asumiendo la tarea de la cooperación y de los ajustes de objetivos y responsabilidades propios. Como limitaciones se puede decir, dado el tratamiento formal o metódico de la hermenéutica, que se circunscribe al contenido de los horizontes en cada caso particular, en cada ejemplo. Aunque el caso aquí aludido se puede tomar como modelo ello no será suficiente para otras circunstancias. Lo importante, en todo asunto, es a la fusión horizontes. Ésta se da en la declaratoria de una producción de sentido significativa: «lo reconozco». Pero cabe precisar si dicho reconocimiento ocurre como idéntico o como igual o como distinto. Reconocer a otro como idéntico es altamente cuestionable; se eliminan las individualidades y se homogeniza de manera esencialista. Reconocer una igualdad sin matices históricos, distinción de capacidades culturales y posibilidades de oportunidades representaría un grado menor de inculturación, pero de todos modos una homogenización cuestionable. Ahora bien, inclinarse por la diferencia resulta una posición de mayor apertura porque «La Diferencia...implica la responsabilidad por y hacia lo distinto de los otros $»^{49}$. Es decir, respeto y reconocimiento no son actitudes que han de quedarse en la pasividad, involucran la solidaridad y subsidiariedad en tanto promoción de identidades y culturas diferentes.

El reconocimiento implica la diferenciación de las minorías culturales dotándolas de una posibilidad incluyente o, mejor aún, de su propia elección de realización. Sólo así pueden defenderse los horizontes de significatividad expuestos a panoramas diversos, y sólo así pueden promoverse y enriquecerse mutuamente. Los cambios de significatividad, la fusión de horizontes, no sólo resguardan la identidad cuando hay buenas razones para ello, sino deben mejorarla cuando sea el caso. Ejemplifiquemos, otra vez, con el encuentro entre los «Tlamatinime» y los hermanos franciscanos; cuando los aztecas declararon: «Totecujoane, ca njcan ticcuj nica ticana in rubquj amotlatoltrin, manoco tlacua in amoiollotįin. [que en Nahuatl quiere decir] Señores nuestros, aquí cogemos, aquí tomamos

49 J. AGUIRRE, «Ciudadanía bermenéutica. Un enfoque que rebasa el multiculturalismo de la aldea global en la sociedad del conocimiento», 97. 
tal como es, vuestra palabra. Que no se altere vuestro corazón, que esté tranquilo el nuestro» ${ }^{50}$; estos sabios aztecas simplemente obtuvieron desde su propio horizonte el sentido de verdad de sus interlocutores y sin perder su identidad y mentalidad guerrera se convirtieron, con lo cual asumieron los primeros pasos hacia un nuevo horizonte cultural.

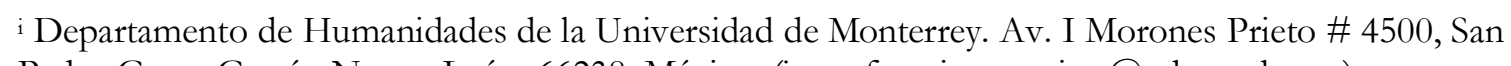
Pedro Garza García, Nuevo León, 66238, México. (jorge.francisco.aguirre@udem.edu.mx)

${ }^{50}$ El coloquio de los doce, 160 en Náhuatl, 161 en castellano. Ver referencia en nota 33. 